\title{
Susceptibility of Bifidobacteria of Animal Origin to Selected Antimicrobial Agents
}

\author{
Sigrid Mayrhofer, Christiane Mair, Wolfgang Kneifel, and Konrad J. Domig \\ Department of Food Sciences and Technology, Institute of Food Sciences, BOKU-University of Natural Resources and Life Sciences, \\ Muthgasse 18, 1190 Vienna, Austria
}

Correspondence should be addressed to Konrad J. Domig, konrad.domig@boku.ac.at

Received 30 November 2010; Accepted 28 January 2011

Academic Editor: Spyros Pournaras

Copyright ( $\odot 2011$ Sigrid Mayrhofer et al. This is an open access article distributed under the Creative Commons Attribution License, which permits unrestricted use, distribution, and reproduction in any medium, provided the original work is properly cited.

\begin{abstract}
Strains of the genus Bifidobacterium are frequently used as probiotics, for which the absence of acquired antimicrobial resistance has become an important safety criterion. This clarifies the need for antibiotic susceptibility data for bifidobacteria. Based on a recently published standard for antimicrobial susceptibility testing of bifidobacteria with broth microdilution method, the range of susceptibility to selected antibiotics in 117 animal bifidobacterial strains was examined. Narrow unimodal MIC distributions either situated at the low-end (chloramphenicol, linezolid, and quinupristin/dalfopristin) or high-end (kanamycin, neomycin) concentration range could be detected. In contrast, the MIC distribution of trimethoprim was multimodal. Data derived from this study can be used as a basis for reviewing or verifying present microbiological breakpoints suggested by regulatory agencies to assess the safety of these micro-organisms intended for the use in probiotics.
\end{abstract}

\section{Introduction}

Probiotics are generally defined as "live micro-organisms which confer a health benefit on the host when administered in adequate amounts" [1]. There is considerable interest in probiotics for a variety of medical conditions, and millions of people around the world consume probiotic medications or foods daily for perceived health benefits [2]. Next to lactobacilli, members of the genus Bifidobacterium (B.) are frequently incorporated in probiotic products [3]. Although they have generally been regarded as safe (GRAS), there are theoretical concerns regarding their safety [2]. These concerns include the potential for transmigration and consequently the occurrence of diseases [2]. Hence, bifidobacteria have already been isolated from various clinical samples and reported as potential pathogens $[4,5]$. Additionally, the potential transfer of antibiotic resistance genes from probiotic bacteria to commensals or potential pathogens within the gastrointestinal flora is taken very seriously $[6,7]$.
Thus, microorganisms used as probiotics for humans or additives in animal nutrition should not contain transferable antimicrobial resistance determinants [8-10]. Hence, the Panel on Additives and Products or Substances Used in Animal Feed (FEEDAP) of the European Food Safety Authority (EFSA) has defined criteria for the assessment of antimicrobial resistance of bacterial strains used as feed additives [11]. According to this panel, all bacteria intended for use as feed additives in Europe must be examined to ensure the susceptibility of the component strains to a relevant range of antibiotics [11]. Additionally, EFSA has proposed the use of the Qualified Presumption of Safety (QPS) status as a safety assessment tool for microorganisms added to food and feed. Within the QPS approach, which is a system similar in concept and purpose to the GRAS definition used in the USA, but modified to take account of different regulatory practices in Europe, the absence of acquired antibiotic resistance traits has to be confirmed for all strains of species with QPS status [12, 13]. 
In contrast to bacteria with clinical significance, standard procedures and breakpoints have been poorly validated for antimicrobial susceptibility testing of non pathogenic bacteria [14]. Because of missing standardized protocols and susceptibility data for lactic acid bacteria and bifidobacteria, risk assessment of these industrially important bacteria has been complicated in the past. The development of the lactic acid bacteria susceptibility test medium [15] proved to be a first major step forward to establish a standardized method for lactic acid bacteria and bifidobacteria. Meanwhile, this medium has been frequently applied for antimicrobial susceptibility testing of bifidobacteria [16-20]. Based on the use of this medium, standard operating procedures for antimicrobial susceptibility testing of bifidobacteria have been proposed [21] and were recently made available as ISO 10932/IDF 233 standard [22].

The occurrence of antimicrobial resistance in animal strains of B. animalis, B. pseudolongum, and B. thermophilum to seven antibiotics (i.e., ampicillin, clindamycin, erythromycin, gentamicin, streptomycin, tetracycline, and vancomycin) has been already determined [16, 17]. As up to 13 antibiotics were proposed by EFSA at the time of investigation [23], the susceptibility of strains of these Bifidobacterium species to the remaining antimicrobial agents chloramphenicol, kanamycin, linezolid, neomycin, quinupristin/dalfopristin, and trimethoprim was examined within this study. The obtained data may serve as basis for the definition of microbiological breakpoints for bifidobacteria. Furthermore, data could be used to eradicate of bifidobacteria from infections, although little is known about their pathogenic potential [4]. Comparing antimicrobial susceptibility data of human and animal strains, which were tested with the same medium, resistances were more prevalent in strains of animal origin [24]. The development of bacterial resistance in livestock may be favored due to the use of antibiotics throughout whole periods of life and widely used prophylaxis with medicated feeding stuff at low doses [25]. Thus, the spread of antimicrobial resistances in bifidobacteria could be better predicted by investigating animal strains.

\section{Materials and Methods}

2.1. Bacterial Strains and Growth Conditions. A total of 112 bifidobacteria of animal origin, isolated during the EU project BIFID (CT-2000-00805) [26], were included in this study belonging to the species: $B$. animalis $(n=8), B$. pseudolongum $(n=33)$, and B. thermophilum $(n=71)$. The identification of the isolates at strain and species level was previously described by Mättö et al. [16] and Mayrhofer et al. [17]. The following BCCM/LMG microbial collection strains (University Gent, Belgium) were additionally tested as reference microorganisms: B. pseudolongum subsp. globosum LMG 11569 (ATCC 25865), B. pseudolongum subsp. globosum LMG 11614 (ATCC 25864), B. pseudolongum subsp. pseudolongum LMG 11594, B. thermophilum LMG 21813 (ATCC 25525; type strain), and B. thermophilum LMG 11574 (ATCC 25866).
Bacteria were maintained at $-80^{\circ} \mathrm{C}$, resuscitated in MRS broth (Oxoid, Hampshire, UK) supplemented with $0.5 \mathrm{~g} /$ liter cysteine-HCl (AppliChem, Darmstadt, Germany), and subcultured on the Lactic acid bacteria Susceptibility test Medium for bifidobacteria (LSM-C). This medium consists of $90 \%$ Isosensitest broth (Oxoid), 10\% MRS broth (Oxoid), and 1.5\% Agar Bacteriological (Oxoid) supplemented with $0.3 \mathrm{~g} /$ liter cysteine-HCl (LSM-C) [15]. All incubations were performed in an anaerobic cabinet $\left(80 \% \mathrm{~N}_{2}, 10 \% \mathrm{CO}_{2}\right.$ and $10 \% \mathrm{H}_{2}$; Scholzen Technik, Switzerland) at $37^{\circ} \mathrm{C}$.

2.2. Antimicrobial Susceptibility Testing. The minimum inhibitory concentrations (MICs) of the antimicrobial agents chloramphenicol, kanamycin, linezolid, neomycin, quinupristin/dalfopristin, and trimethoprim were determined by broth microdilution according to the ISO 10932/IDF 233 standard [22] with minor modifications. With the exception of quinupristin/dalfopristin (Sanalog, Kist, Germany) and linezolid (Pfizer, New York, USA), all antibiotics originated from Sigma-Aldrich (Daint Louis, Missouri, USA). All antibiotics except for chloramphenicol and trimethoprim were dissolved in water for preparing stock solutions of $1280 \mu \mathrm{g} / \mathrm{mL}$. To dissolve chloramphenicol 95\% ethanol was needed, whereas $0.05 \mathrm{M} \mathrm{HCl}$ was required for trimethoprim. These solvents were used in volumes as low as possible, and water was finally added to receive the desired volume of the stock solution. Subsequently, stock solutions were diluted in LSM-C broth to obtain solutions with preliminary concentrations in the range of $0.25-256 \mu \mathrm{g} / \mathrm{mL}$. Of these, $50 \mu \mathrm{l}$ were dispensed in the wells of the microtiter plates.

Bacterial inocula were prepared by suspending colonies from $48 \mathrm{~h}$ incubated LSM-C medium to $5 \mathrm{~mL} 0.85 \% \mathrm{NaCl}$ solution. Subsequently, inocula were adjusted to McFarland standard 1 and diluted 1:500 in LSM-C broth for inoculation of microdilution plates by adding $50 \mu \mathrm{l}$ of diluted inoculum to each well. This resulted in a final antibiotic concentration of $0.12-128 \mu \mathrm{g} / \mathrm{mL}$.

After incubating plates under anaerobic conditions at $37^{\circ} \mathrm{C}$ for 48 hours, the MIC value was read as the lowest concentration of an antimicrobial agent in which visible growth was inhibited.

The accuracy of susceptibility testing was monitored by parallel use of the quality control strain Enterococcus faecalis ATCC 29212.

\section{Results and Discussion}

The antimicrobial susceptibility of $8 \mathrm{~B}$. animalis, $36 \mathrm{~B}$. pseudolongum, and $73 \mathrm{~B}$. thermophilum strains, including five reference strains, to chloramphenicol, kanamycin, linezolid, neomycin, quinupristin/dalfopristin, and trimethoprim is summarized in Table 1 . MICs $(\mu \mathrm{g} / \mathrm{mL})$ are reported in terms of the MIC range, MIC $_{50}$ (MIC that inhibited $50 \%$ of the tested strains), and $\mathrm{MIC}_{90}$ (MIC that inhibited $90 \%$ of the tested strains). Accordingly, no marked difference in the MIC distributions between the different species was observed for chloramphenicol, kanamycin, linezolid, neomycin, and quinupristin/dalfopristin. For these antimicrobial agents 
TABLE 1: Susceptibility of 8 B. animalis, 36. B. pseudolongum, and 73 B. thermophilum strains to selected antimicrobial agents as determined by the broth microdilution method using LSM-C medium.

\begin{tabular}{|c|c|c|c|c|}
\hline \multirow{2}{*}{ Antibiotic } & \multirow{2}{*}{ Species } & \multicolumn{3}{|c|}{$\operatorname{MIC}(\mu \mathrm{g} / \mathrm{mL})$} \\
\hline & & MIC range & $\mathrm{MIC}_{50}$ & $\mathrm{MIC}_{90}$ \\
\hline \multirow[t]{3}{*}{ Chloramphenicol } & B. animalis & $2-4$ & 2 & 4 \\
\hline & B. pseudolongum & $1-2$ & 1 & 2 \\
\hline & B. thermophilum & $0.5-2$ & 1 & 2 \\
\hline \multirow[t]{3}{*}{ Kanamycin } & B. animalis & $>128$ & $>128$ & $>128$ \\
\hline & B. pseudolongum & $\geq 128$ & $>128$ & $>128$ \\
\hline & B. thermophilum & $\geq 128$ & $>128$ & $>128$ \\
\hline \multirow[t]{3}{*}{ Linezolid } & B. animalis & $0.5-2$ & 1 & 2 \\
\hline & B. pseudolongum & $0.5-2$ & 1 & 1 \\
\hline & B. thermophilum & $0.5-1$ & 0.5 & 1 \\
\hline \multirow[t]{3}{*}{ Neomycin } & B. animalis & $32->128$ & 64 & $>128$ \\
\hline & B. pseudolongum & $16->128$ & 64 & $>128$ \\
\hline & B. thermophilum & $16->128$ & 128 & $>128$ \\
\hline Quinupristin/ & B. animalis & $\leq 0.12$ & $\leq 0.12$ & $\leq 0.12$ \\
\hline \multirow[t]{2}{*}{ Dalfopristin } & B. pseudolongum & $\leq 0.12-0.25$ & $\leq 0.12$ & 0.25 \\
\hline & B. thermophilum & $\leq 0.12-0.25$ & $\leq 0.12$ & 0.25 \\
\hline \multirow[t]{3}{*}{ Trimethoprim } & B. animalis & $\leq 0.12$ & $\leq 0.12$ & $\leq 0.12$ \\
\hline & B. pseudolongum & $\leq 0.12-32$ & $\leq 0.12$ & 4 \\
\hline & B. thermophilum & $0.5->128$ & 8 & 128 \\
\hline
\end{tabular}

$\mathrm{MIC}_{50}$ and $\mathrm{MIC}_{90}: \mathrm{MICs}(\mu \mathrm{g} / \mathrm{mL})$ that inhibited $50 \%$ and $90 \%$ of the number of strains tested, respectively.

narrow unimodal MIC distributions either at the low-end concentration range (i.e., for chloramphenicol, linezolid, and quinupristin/dalfopristin) or at the high-end concentration range (i.e., for kanamycin and neomycin) were determined (Figures 1(a)-1(e)). A unimodal distribution describes a population, which is either uniformly susceptible (i.e., for chloramphenicol, linezolid, and quinupristin/dalfopristin) or resistant (i.e., for kanamycin and neomycin) [27, 28]. Next to a unimodal distribution MIC values, obtained by susceptibility testing of a defined population of strains, can also follow a bimodal or multimodal distribution [29]. For trimethoprim a multimodal distribution with three different subpopulations was identified: one with very low MICs $(\leq 0.12 \mu \mathrm{g} / \mathrm{mL})$, another one with higher MICs (0.5$16 \mu \mathrm{g} / \mathrm{mL})$, and a last one with high MICs $(32->128 \mu \mathrm{g} / \mathrm{mL})$ (Figure 1(f)). While B. animalis strains generally had lower trimethoprim MICs $(\leq 0.12 \mu \mathrm{g} / \mathrm{mL})$, the highest MICs were detected for $B$. thermophilum strains $(0.5->128 \mu \mathrm{g} / \mathrm{mL})$. The MIC values of $B$. pseudolongum strains were between $\leq 0.12 \mu \mathrm{g} / \mathrm{mL}$ and $32 \mu \mathrm{g} / \mathrm{mL}$.

In order to allow the interpretation of antimicrobial susceptibility profiles of bifidobacteria used in food and feed applications, microbiological breakpoints are needed for categorizing susceptible or resistant strains. Especially bimodal distributions of MIC values play an important role in determining the microbiological breakpoint. Nevertheless, also unimodal and multimodal distributions can support the definition of microbiological breakpoints to distinguish strains with acquired resistance from the native, susceptible population. Beside this, MICs for determining microbiological breakpoints are only meaningful when the methods and conditions of the test are known [30]. It is for this reason that the development of an international standard reference method for determining MICs for bifidobacteria was recently proposed [22]. Thus, data obtained in this study, following the newest method developments concerning antimicrobial susceptibility testing of bifidobacteria, can be used as a basis for reviewing or verifying present microbiological breakpoints for bifidobacteria to assess the safety of microorganisms intended for use in food and feed applications.

According to the literature, bifidobacteria are usually sensitive to chloramphenicol. Normal MICs to this antimicrobial agent using various test techniques and media have been reported to range between 0.5 and $8 \mu \mathrm{g} / \mathrm{mL}$ [31-37]. Only once in the literature, five strains belonging to the species $B$. infantis, $B$. longum, and $B$. suis as well as one Bifidobacterium sp. isolate with higher MICs up to $64 \mu \mathrm{g} / \mathrm{mL}$ were detected by Kheadr et al. [38]. However, these authors concluded that the strains may still be sensitive. Thus, strains with acquired resistance have not been detected until now. Using the recommended LSM-C medium [22] and the same [20] or similar conditions [19] for antimicrobial susceptibility testing, a chloramphenicol MIC $\leq 2 \mu \mathrm{g} / \mathrm{mL}$ for one B. thermophilum strain [19] or MICs between 1 and $2 \mu \mathrm{g} / \mathrm{mL}$ for ten B. longum strains [20] could be observed. As only a small number of strains were tested within the above-mentioned studies, the widening of the MIC distribution from 0.5 to $4 \mu \mathrm{g} / \mathrm{mL}$ (Figure 1(a)) by investigating 


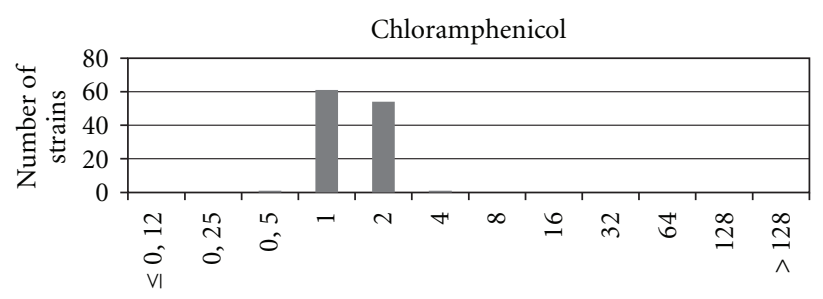

$\operatorname{MIC}(\mu \mathrm{g} / \mathrm{mL})$

(a)

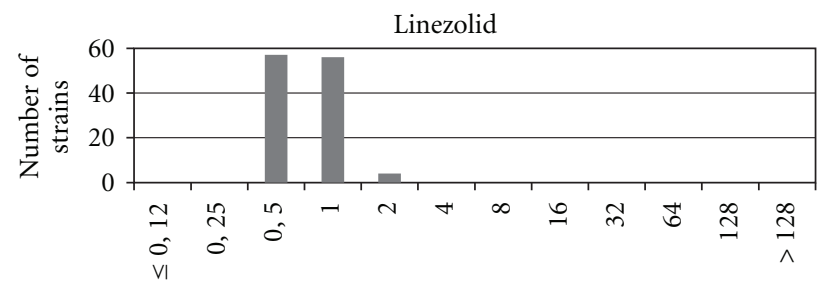

$\operatorname{MIC}(\mu \mathrm{g} / \mathrm{mL})$

(c)

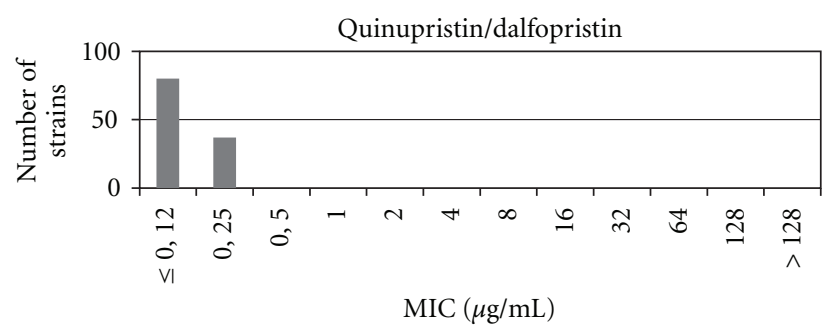

(e)

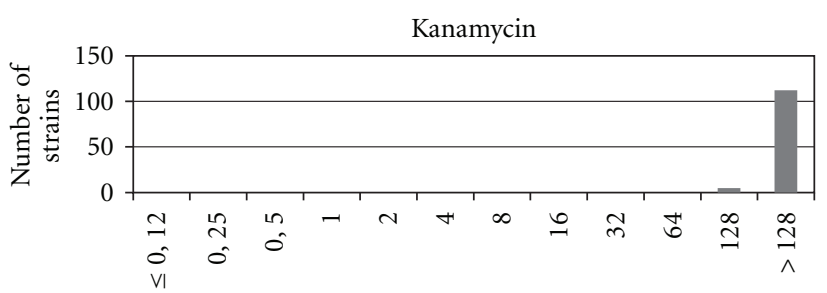

$\operatorname{MIC}(\mu \mathrm{g} / \mathrm{mL})$

(b)

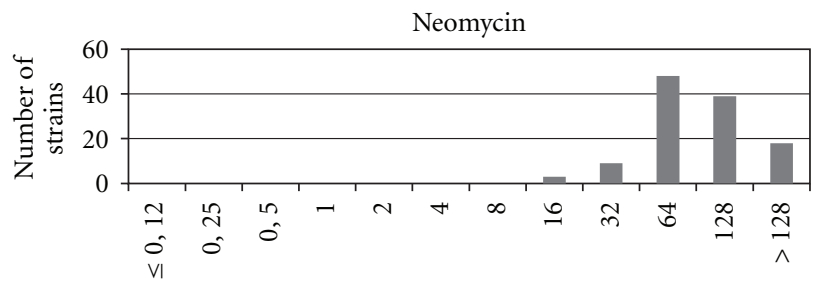

$\operatorname{MIC}(\mu \mathrm{g} / \mathrm{mL})$

(d)

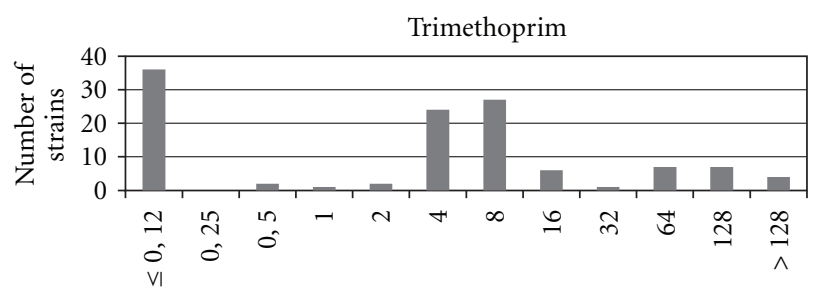

$\operatorname{MIC}(\mu \mathrm{g} / \mathrm{mL})$

(f)

FIGURE 1: Distribution of minimum inhibitory concentrations (MICs) for (a) chloramphenicol, (b) kanamycin, (c) linezolid, (d) neomycin, (e) quinupristin/dalfopristin, and (f) trimethorpim in 8 B. animalis, 36. B. pseudolongum, and 73 B. thermophilum strains as determined with the microdilution broth method using LSM-C medium.

more than 100 strains in this study is obvious. Applying the recommended breakpoint of EFSA [11], all strains of the unimodal distribution are categorized as susceptible, approving the recent EFSA microbiological breakpoint for chloramphenicol.

Most bifidobacteria have been reported as resistant to aminoglycosides because of the lack of cytochrome-mediated drug transport system, resulting in a failure of the drug to reach its target [39]. The resistance of the tested strains to gentamicin and streptomycin has already been reported before $[16,17]$. Correspondingly, all strains were resistant to kanamycin $(128->128 \mu \mathrm{g} / \mathrm{mL}$, Figure $1(\mathrm{~b}))$ and neomycin $(16->128 \mu \mathrm{g} / \mathrm{mL}$, Figure $1(\mathrm{~d}))$. The particular resistance of bifidobacteria to kanamycin is well known, and MICs between 64 and $>1024 \mu \mathrm{g} / \mathrm{mL}$ were described for this antimicrobial agent, whereas for neomycin MICs lay between 16 and $>1024 \mu \mathrm{g} / \mathrm{mL}$ testing a large number of species such as $B$. bifidum, $B$. breve, $B$. catenulatum, $B$. infantis, $B$. longum, B. suis, B. thermophilum, and others [32, 35-37]. Using the LSM-C medium, the antimicrobial susceptibility to kanamycin was only tested by Kushiro et al. [20] and Klose et al. [19]. Whereas Kushiro et al. [20] received MICs between 128 and $512 \mu \mathrm{g} / \mathrm{mL}$ for ten $B$. longum strains, the tested B. thermophilum strain of Klose et al. [19] displayed an MIC value of $64 \mu \mathrm{g} / \mathrm{mL}$. The lower MIC value detected by Klose et al. may be due to other testing conditions (i.e., 24 hours instead of 48 hours of incubation), underlining the importance of controlled and standardized conditions for susceptibility testing [40]. While breakpoints for gentamicin and streptomycin are indicated in the EFSA document [11], none is required for kanamycin or specified for neomycin.

Low level, unimodal MIC distributions between 0.5 and $1 \mu \mathrm{g} / \mathrm{mL}$ have been reported for linezolid and different bifidobacterial species, suggesting all bifidobacteria are susceptible to this antibiotic $[37,41]$. This is in good accordance with our results, since all tested strains were inhibited by a linezolid concentration lower than $4 \mu \mathrm{g} / \mathrm{mL}$ (Figure 1(c)). Ten B. longum strains, also tested using the same medium and conditions, displayed MIC values of 0.5 and $1 \mu \mathrm{g} / \mathrm{mL}$ [20]. As the nonmutational resistance to linezolid, which is due to the acquisition of the $c f r$ gene, is extremely rare and also confers resistance to chloramphenicol [42, 43], testing for this antimicrobial agent was no longer considered as relevant by EFSA [11]. Checking for chloramphenicol resistance should efficiently cover the hazard of an acquired resistance to linezolid [11].

The in vitro susceptibility of bifidobacteria to quinupristindalfopristin has been rarely studied. Only two previous reports showed that bifidobacteria are susceptible to this semisynthetic mixture by testing 100 strains of 11 
bifidobacterial species by agar overlay disc diffusion [18] and one B. thermophilum strain by broth microdilution [19] using the same test medium (LSM-C). The obtained MIC value of $0.5 \mu \mathrm{g} / \mathrm{mL}$ by Klose et al. [19] was one dilution step higher than the MIC range $(\leq 0.12-0.25 \mu \mathrm{g} / \mathrm{mL})$ received within this study (Figure 1(e)). The EFSA breakpoint of $1 \mu \mathrm{g} / \mathrm{mL}$ to quinupristin-dalfopristin appears to be applicable for bifidobacteria [11].

Reduced susceptibility of bifidobacteria towards trimethoprim was described by Ouoba et al. [37]. Susceptibility was also found to be variable and strain-specific by Masco et al. investigating 100 strains of 11 bifidobacterial species [18] or to be $\geq 32 \mu \mathrm{g} / \mathrm{mL}$ by Kushiro et al. testing $10 B$. longum strains [20], also using the same medium as within this study. Hence, a variable but species-specific susceptibility was detected, nearly covering the whole concentration range tested (Figure 1(f)). Also a wide range of trimethoprim MICs with no clear breakpoint values was identified for certain Lactobacillus species [44]. This was led back to the presence of antagonistic components in the medium, complicating susceptibility testing concerning trimethoprim $[11,15]$. Thus, MIC testing of trimethoprim was no longer considered as relevant by EFSA [11].

\section{Conclusion}

In this study, the recently published ISO 10932/IDF 233 standard [22] was used to provide susceptibility data on the basis of a representative number of animal bifidobacteria. These data could be used for reviewing or verifying present microbiological breakpoints suggested by regulatory agencies to assess the safety of microorganisms intended for the use in probiotics. Nevertheless, more data including MIC values of human bifidobacteria for these antimicrobial agents applying the same testing conditions are needed to obtain adequate breakpoints for differentiating susceptible bacteria from those with acquired resistance. Additionally, a broad screening of resistance genes using molecular tools would also be of importance for the definition of applicable breakpoints.

\section{Acknowledgements}

This study was performed as a part of the EU Project "ACE-ART" (CT-2003-506214) within the 6th framework. Françoise Gavini and Matthias Upmann are gratefully acknowledged for providing the strains isolated in the EU Project "BIFID" (CT-2000-00805). Pfizer is thanked for providing linezolid.

\section{References}

[1] FAO/WHO, "Health and nutritional properties of probiotics in food including powder milk with live lactic acid bacteria," Report of a Joint FAO/WHO Expert Group, Cordoba, Argentina, Food and Agricultural Organization of the United Nations, World Health Organization, 2001, http://www.who. int/foodsafety/publications/fs_management/en/probiotics.pdf.
[2] D. R. Snydman, "The safety of probiotics," Clinical Infectious Diseases, vol. 46, no. 2, supplement, pp. S104-S111, 2008.

[3] S. C. Leahy, D. G. Higgins, G. F. Fitzgerald, and D. Van Sinderen, "Getting better with bifidobacteria," Journal of Applied Microbiology, vol. 98, no. 6, pp. 1303-1315, 2005.

[4] I. Brook, "Isolation of non-sporing anaerobic rods from infections in children," Journal of Medical Microbiology, vol. 45, no. 1, pp. 21-26, 1996.

[5] I. Brook, "Pericarditis caused by anaerobic bacteria," International Journal of Antimicrobial Agents, vol. 33, no. 4, pp. 297300, 2009.

[6] M. Teuber, L. Meile, and F. Schwarz, "Acquired antibiotic resistance in lactic acid bacteria from food," Antonie van Leeuwenhoek, vol. 76, no. 1-4, pp. 115-137, 1999.

[7] V. Vankerckhoven, G. Huys, M. Vancanneyt et al., "Biosafety assessment of probiotics used for human consumption: recommendations from the EU-PROSAFE project," Trends in Food Science and Technology, vol. 19, no. 2, pp. 102-114, 2008.

[8] FAO/WHO, "Guidelines for the evaluation of probiotics in food," Food Agriculture Organization of the United Nations and World Health Organization Working Group Report, London, Canada, pp. 1-11, 2002.

[9] A. Henriksson, T. Borody, and R. Clancy, "Probiotics under the regulatory microscope," Expert Opinion on Drug Safety, vol. 4, no. 6, pp. 1135-1143, 2005.

[10] A. von Wright, "Regulating the safety of probiotics - The European approach," Current Pharmaceutical Design, vol. 11, no. 1, pp. 17-23, 2005.

[11] EFSA (European Food Safety Authority), "Update of the criteria used in the assessment of bacterial resistance to antibiotics of human and veterinary importance," The EFSA Journal, vol. 732, pp. 1-15, 2008.

[12] EFSA (European Food Safety Authority), "EFSA scientific colloquium summary report: QPS - qualified presumption of safety of microorganisms in food and feed," 2004, http:// www.efsa.europa.eu/en/colloquiareports/colloquiaqps.htm.

[13] EFSA (European Food Safety Authority), "Opinion of the Scientific Committee on a request from EFSA on the introduction of a Qualified Presumption of Safety (QPS) approach for assessment of selected microorganisms referred to EFSA," The EFSA Journal, vol. 587, pp. 1-16, 2007.

[14] J. Mättö, M. L. Suihko, and M. Saarela, "Comparison of three test media for antimicrobial susceptibility testing of bifidobacteria using the Etest method," International Journal of Antimicrobial Agents, vol. 28, no. 1, pp. 42-48, 2006.

[15] I. Klare, C. Konstabel, S. Müller-Bertling et al., "Evaluation of new broth media for microdilution antibiotic susceptibility testing of lactobacilli, pediococci, lactococci, and bifidobacteria," Applied and Environmental Microbiology, vol. 71, no. 12, pp. 8982-8986, 2005.

[16] J. Mättö, A. H. A. M. van Hoek, K. J. Domig et al., "Susceptibility of human and probiotic Bifidobacterium spp. to selected antibiotics as determined by the Etest method," International Dairy Journal, vol. 17, no. 9, pp. 1123-1131, 2007.

[17] S. Mayrhofer, K. J. Domig, E. Amtmann et al., "Antibiotic susceptibility of Bifidobacterium thermophilum and Bifidobacterium pseudolongum isolates from animal sources," Journal of Food Protection, vol. 70, no. 1, pp. 119-124, 2007.

[18] L. Masco, K. Van Hoorde, E. De Brandt, J. Swings, and G. Huys, "Antimicrobial susceptibility of Bifidobacterium strains from humans, animals and probiotic products," Journal of Antimicrobial Chemotherapy, vol. 58, no. 1, pp. 85-94, 2006.

[19] V. Klose, R. Bruckbeck, S. Henikl, G. Schatzmayr, and A. P. Loibner, "Identification and antimicrobial susceptibility 
of porcine bacteria that inhibit the growth of Brachyspira hyodysenteriae in vitro," Journal of Applied Microbiology, vol. 108, no. 4, pp. 1271-1280, 2010.

[20] A. Kushiro, C. Chervaux, S. Cools-Portier et al., "Antimicrobial susceptibility testing of lactic acid bacteria and bifidobacteria by broth microdilution method and Etest," International Journal of Food Microbiology, vol. 132, no. 1, pp. 54-58, 2009.

[21] G. Huys, K. D'Haene, M. Cnockaert et al., "Intra- and interlaboratory performances of two commercial antimicrobial susceptibility testing methods for bifidobacteria and nonenterococcal lactic acid bacteria," Antimicrobial Agents and Chemotherapy, vol. 54, no. 6, pp. 2567-2574, 2010.

[22] ISO (International Organization for Standardization), "Milk and milk products-determination of the minimal inhibitory concentration (MIC) of antibiotics applicable to bifidobacteria and non-enterococcal lactic acid bacteria (LAB)," ISO 10932/IDF 233 standard, 2010.

[23] EFSA (European Food Safety Authority), "Opinion of the Scientific Panel on Additives and Products or Substances Used in Animal Feed (FEEDAP) on the updating of the criteria used in assessment of bacteria for resistance to antibiotics of human and veterinary importance," The EFSA Journal, vol. 223, pp. 112, 2005.

[24] B. Mayo, S. Mayrhofer, S. Delgado, and K. J. Domig, "Antibiotic resistance/susceptibility profiles of bifidobacteria and molecular analysis of atypical resistances," in BifidobacteriaGenomics and Molecular Aspects, B. Mayo and D. van Sinderen, Eds., pp. 195-215, Caister Academic Press, Norwich, UK, 2010.

[25] F. R. Ungemach, "Figures on quantities of antibacterials used for different purposes in the EU countries and interpretation," Acta veterinaria Scandinavica. Supplementum, vol. 93, pp. 8997, 2000.

[26] F. Gavini, V. Delcenserie, K. Kopeinig et al., "Bifidobacterium species isolated from animal feces and from beef and pork meat," Journal of Food Protection, vol. 69, no. 4, pp. 871-877, 2006.

[27] F. Goldstein, C. J. Soussy, and A. Thabaut, "Definition of the clinical antibacterial spectrum of activity," Clinical Microbiology and Infection, vol. 2, no. 1, supplement, pp. S40-S45, 1996.

[28] J. Sirot, P. Courvalin, and C. J. Soussy, "Definition and determination of in vitro antibiotic susceptibility breakpoints for bacteria," Clinical Microbiology and Infection, vol. 2, no. 1, supplement, pp. S5-S10, 1996.

[29] J. W. Mouton, "Breakpoints: current practice and future perspectives," International Journal of Antimicrobial Agents, vol. 19, no. 4, pp. 323-331, 2002.

[30] J. Turnidge and D. L. Paterson, "Setting and revising antibacterial susceptibility breakpoints," Clinical Microbiology Reviews, vol. 20, no. 3, pp. 391-408, 2007.

[31] M. S. Ammor, A. B. Flórez, A. H. A. M. van Hoek et al., "Molecular characterization of intrinsic and acquired antibiotic resistance in lactic acid bacteria and bifidobacteria," Journal of Molecular Microbiology and Biotechnology, vol. 14, no. 1-3, pp. 6-15, 2007.

[32] M. R. D’Aimmo, M. Modesto, and B. Biavati, "Antibiotic resistance of lactic acid bacteria and Bifidobacterium spp. isolated from dairy and pharmaceutical products," International Journal of Food Microbiology, vol. 115, no. 1, pp. 35-42, 2007.

[33] S. Delgado, A. B. Flórez, and B. Mayo, "Antibiotic susceptibility of Lactobacillus and Bifidobacterium species from the human gastrointestinal tract," Current Microbiology, vol. 50, no. 4, pp. 202-207, 2005.
[34] S. Delgado, E. O’Sullivan, G. Fitzgerald, and B. Mayo, "In vitro evaluation of the probiotic properties of human intestinal Bifidobacterium species and selection of new probiotic candidates," Journal of Applied Microbiology, vol. 104, no. 4, pp. 1119-1127, 2008.

[35] K. S. Lim, C. S. Huh, and Y. J. Baek, "Antimicrobial susceptibility of bifidobacteria," Journal of Dairy Science, vol. 76, no. 8, pp. 2168-2174, 1993.

[36] D. Matteuzzi, F. Crociani, and P. Brigidi, "Antimicrobial susceptibility of Bifidobacterium," Annales de Microbiologie (Paris), vol. 134, no. 3, pp. 339-349, 1983.

[37] L. I. I. Ouoba, V. Lei, and L. B. Jensen, "Resistance of potential probiotic lactic acid bacteria and bifidobacteria of African and European origin to antimicrobials: determination and transferability of the resistance genes to other bacteria," International Journal of Food Microbiology, vol. 121, no. 2, pp. 217-224, 2008.

[38] E. Kheadr, N. Bernoussi, C. Lacroix, and I. Fliss, "Comparison of the sensitivity of commercial strains and infant isolates of bifidobacteria to antibiotics and bacteriocins," International Dairy Journal, vol. 14, no. 12, pp. 1041-1053, 2004.

[39] L. E. Bryan, S. K. Kowand, and H. M. Van den Elzen, "Mechanism of aminoglycoside antibiotic resistance in anaerobic bacteria: Clostridium perfringens and Bacteroides fragilis," Antimicrobial Agents and Chemotherapy, vol. 15, no. 1, pp. 713, 1979.

[40] M. Egervärn, H. Lindmark, S. Roos, G. Huys, and S. Lindgren, "Effects of inoculum size and incubation time on broth microdilution susceptibility testing of lactic acid bacteria," Antimicrobial Agents and Chemotherapy, vol. 51, no. 1, pp. 394-396, 2007.

[41] C. Moubareck, F. Gavini, L. Vaugien, M. J. Butel, and F. Doucet-Populaire, "Antimicrobial susceptibility of bifidobacteria," Journal of Antimicrobial Chemotherapy, vol. 55, no. 1, pp. 38-44, 2005.

[42] C. A. Arias, M. Vallejo, J. Reyes et al., "Clinical and microbiological aspects of linezolid resistance mediated by the $c f r$ gene encoding a 23S rRNA methyltransferase," Journal of Clinical Microbiology, vol. 46, no. 3, pp. 892-896, 2008.

[43] S. M. Toh, L. Xiong, C. A. Arias et al., "Acquisition of a natural resistance gene renders a clinical strain of methicillin-resistant Staphylococcus aureus resistant to the synthetic antibiotic linezolid," Molecular Microbiology, vol. 64, no. 6, pp. 15061514, 2007.

[44] J. M. Korhonen, Y. Sclivagnotis, and A. V. Wright, "Characterization of dominant cultivable lactobacilli and their antibiotic resistance profiles from faecal samples of weaning piglets," Journal of Applied Microbiology, vol. 103, no. 6, pp. 2496-2503, 2007. 


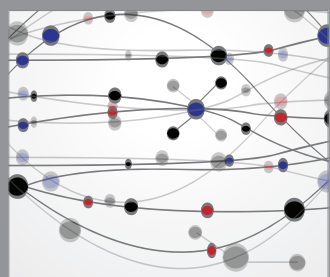

The Scientific World Journal
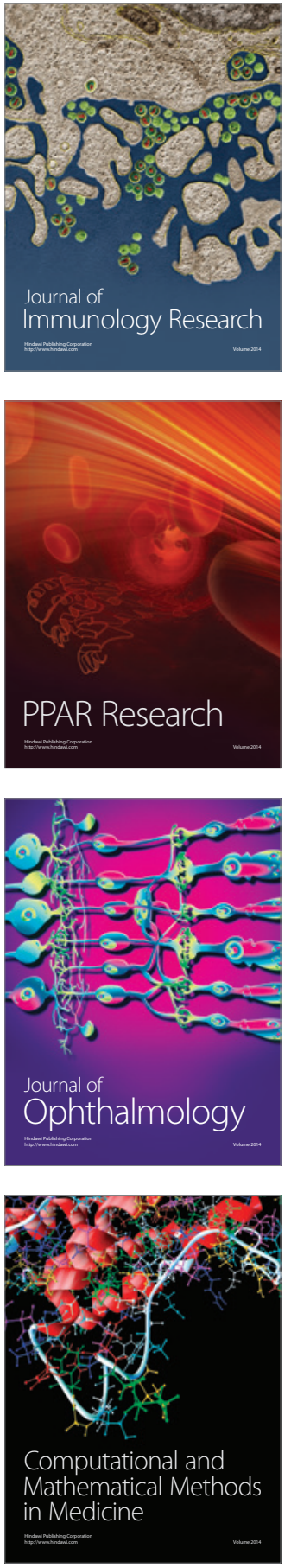

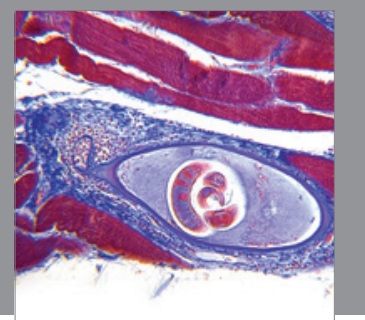

Gastroenterology

Research and Practice
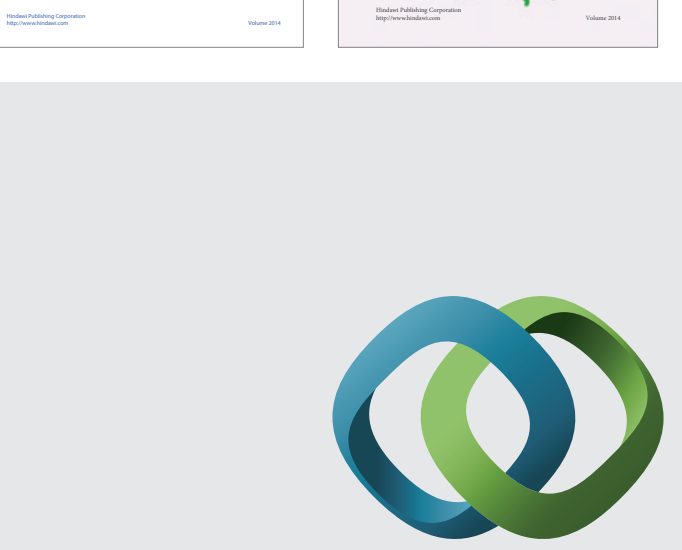

\section{Hindawi}

Submit your manuscripts at

http://www.hindawi.com
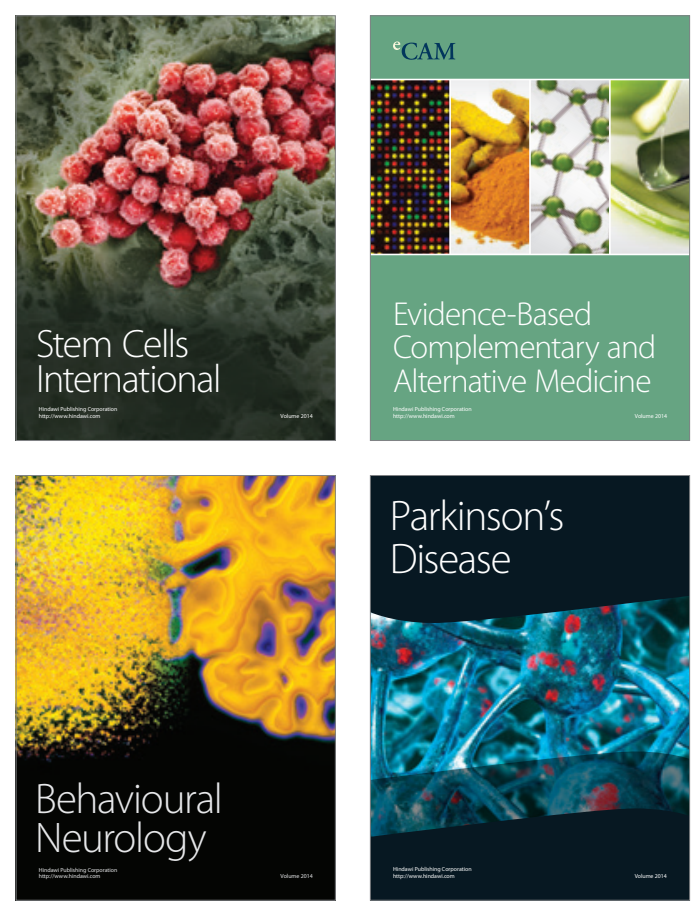

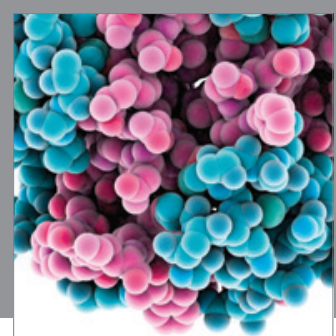

Journal of
Diabetes Research

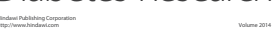

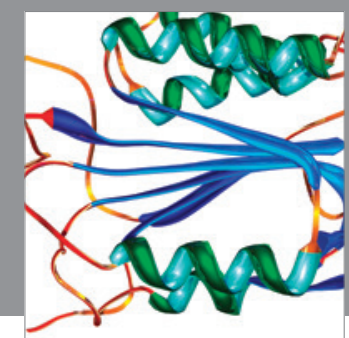

Disease Markers
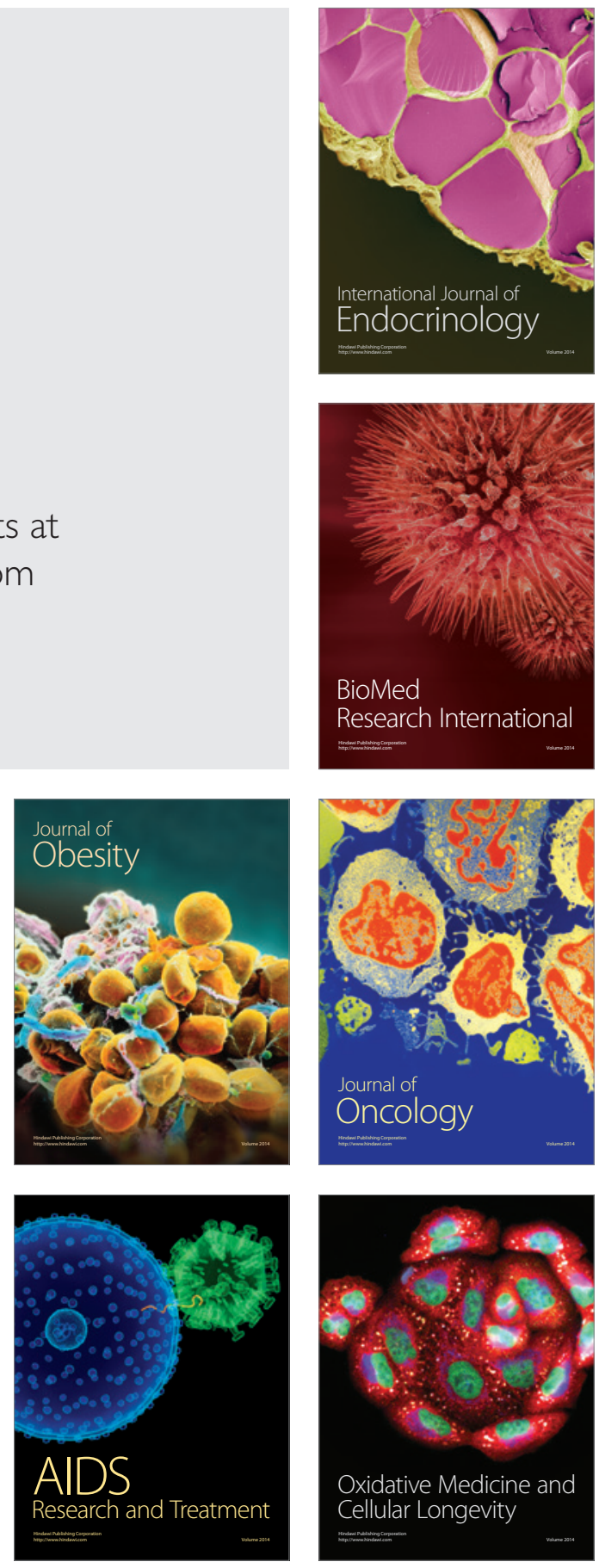